\title{
EDITORIAL
}

\section{Lung function decline in asthma}

\author{
M.R. Sears
}

$\mathbf{P}$ rogressive decline in lung function in asthma has been well recognised but not fully explained. For example, in a Danish population study (the Copenhagen City Heart Study), three measurements of forced expiratory volume in one second (FEV1) were made over 15 yrs in 17,506 subjects, including 1,095 with asthma [1]. Asthmatics showed a decline in FEV1 of $38 \mathrm{~mL} \cdot \mathrm{yr}^{-1}$ compared with $22 \mathrm{~mL} \cdot \mathrm{yr}^{-1}$ in normal individuals. However, accelerated decline is not invariable. Many asthmatics retain normal or close to normal lung function throughout life, showing reversibility from acute worsenings and return to previous function. Conversely, some patients develop "irreversible" asthma, as seen in populationbased studies [2] and in specialist-treated patients whose obstruction persisted despite bronchodilators and oral corticosteroids [3]. In the latter patients, lung function decreased with age, and with duration and severity of asthma. Progressive loss of function can be inexorable despite aggressive therapy, resulting in end-stage respiratory failure that occasionally justifies lung transplantation [4].

Among 228 adults followed up after 21-33 yrs in a clinic in Groningen, the Netherlands, $16 \%$ had irreversible airway obstruction, which was defined as FEV $1<80 \%$ predicted with reversibility $<9 \%$ pred [5]. Irreversible disease was predicted by a lower FEV1, less reversibility and less (rather than greater, as one might have expected) airway hyperresponsiveness (AHR) at initial screening. Patients using regular treatment developed irreversible obstruction less frequently. Loss of lung function has serious consequences. In 89 asthmatics followed over 17 yrs in Perth, Australia, lower lung function, but not initial symptom severity, predicted mortality [6]. The risk of death was higher with decreased FEV1 and increased FEV1 variability, age and treatment requirements.

Both the Melbourne (Australia) [7] and Dunedin (New Zealand) [8] longitudinal studies of the natural history of asthma show that impaired lung function in adult asthmatics often has its origins in childhood. Up to one-third of Dunedin birth cohort study members with persistent wheezing syndromes and AHR in childhood demonstrated a degree of fixed airflow obstruction (or "airway remodelling") in adolescence, evident functionally as a post-bronchodilator FEV1/forced vital capacity (FVC) ratio $>2$ SD below the mean age- and sexspecific values for their nonasthmatic, nonsmoking peers [9].

STATEMENT OF INTEREST: A statement of interest for M.R. Sears can be found at www.erj.ersjournals.com/misc/statements.shtml

CORRESPONDENCE: M.R. Sears, Dept of Medicine, McMaster University, Firestone Institute for Respiratory Health, St Joseph's Healthcare, 50 Charlton Ave E, Hamilton, L8N 4A6, ON, Canada. Fax: 1 9055216132. E-mail: searsm@mcmaster.ca
As the study members transitioned into adulthood, the degree of reversibility decreased further. These changes, representing fixed airflow obstruction, were even more apparent in those with a history of using inhaled corticosteroid (ICS), although it is likely that this represents confounding by indication.

What are the risk factors for decline in lung function with time? Consideration is usually given to the effects of smoking, atopy and baseline lung function (airway calibre and AHR). In a USA study of lung function among young people aged 18-30 yrs followed up over $10 \mathrm{yrs}$, there was an $8.5 \%$ decline in FEV1 in never-smokers without asthma, $10.1 \%$ decline in nonsmokers with asthma, and $11.1 \%$ decline in baseline smokers of $>15$ cigarettes $\cdot$ day $^{-1}$. A synergistic effect was noted in smoking asthmatics with a decline in FEV1 of $17.8 \%$ [10]. While PEAT et al. [2] found no relationship between the rate of decline of FEV1 and age or atopic status, AHR accounted for $9 \%$ and airflow limitation (measured by FEV1/FVC) for $10 \%$ of the variation in the rate of decline. VAN SCHAYCK et al. [11] reported that among 71 adult patients with asthma, atopy and AHR were not associated with the rate of exacerbations, but AHR did contribute to predicting the rate of decline in lung function. In atopic patients, AHR was related to an even more pronounced rate of decline in FEV1 than in nonatopic patients. The slope of post-bronchodilator FEV1 paralleled pre-bronchodilator FEV1, indicating that the loss of function was due to a degree of fixed obstruction and not only acute bronchoconstriction.

Do exacerbations impact the rate of decline of lung function in asthma? In chronic obstructive pulmonary disease, exacerbations clearly contribute to increased rates of lung function decline, systemic effects and premature mortality [12]. While asthma may be associated with accelerated loss of lung function, the role of exacerbations in this process is unknown. This gap in knowledge is addressed in the current issue of the European Respiratory Journal by BAI et al. [13], who have examined data from a historical cohort of 93 nonsmoking patients with moderate-to-severe asthma followed by one physician in an institute in Groningen.

The study period was selected to pre-date the introduction of ICS, which could modify lung function by controlling inflammation over time. Physiological measurements were performed consistently on one spirometer for $\geqslant 5$ yrs with a median followup of 11 yrs. There was a significant association between the frequency of exacerbations (which were defined by an abrupt but recoverable decrease in lung function of $\geqslant 20 \%$ and $500 \mathrm{~mL}$ ) and long-term decline in lung function. Never-smoking individuals with more or less than the median number of exacerbations had a decline in FEV1 of $31.5 \mathrm{~mL} \cdot \mathrm{yr}^{-1}$ and $6.5 \mathrm{~mL} \cdot \mathrm{yr}^{-1}$, respectively. Oral corticosteroid use and lung function at 
baseline were associated with a higher rate of exacerbations during follow-up but, independently of these variables, patients with more frequent exacerbations had a significantly larger annual decline in function. One severe exacerbation predicted an excess decline of $30 \mathrm{~mL} \cdot \mathrm{yr}^{-1}$. BAI et al. [13] conclude that frequent exacerbations lead to excess decline in function, and postulate that this is attributable to inflammation fuelling the processes and pathology of airway remodelling.

What is surprising about the study by BAI et al. [13] is not the association with exacerbations per se, but that it is the first clear report of such an association. The numbers of individuals are small, but the findings from almost 2,000 spirometry measurements over a median of 11 yrs are sufficiently strong to make an association of progressive worsening with frequency of inflammatory episodes in the airway quite plausible. The strengths of the study include the consistency of assessment and of follow-up, and the detailed assessments, including measurements of AHR and serum immunoglobulin E. Severity of AHR, bronchodilator reversibility, blood eosinophil count and age of onset of asthma symptoms did not differ between those with frequent and infrequent exacerbations. However, those with frequent exacerbations had lower lung function at baseline and were more often nonatopic (to house dust mite) than those with less frequent exacerbations.

The mechanisms by which exacerbations increase the decline in function in asthma are postulated by BAI et al. [13] to relate to periods of intense airway inflammation. There are some supporting data for this suggestion. In a UK clinic, asthmatics with severe obstruction (FEV1 $<50 \%$ pred) were older, with longer duration of disease, greater exhaled nitric oxide, higher peripheral blood eosinophils and greater bronchial wall thickening on high-resolution computed tomography (CT) scan compared with those with FEV1 $>80 \%$ pred [14]. Blood eosinophilia and CT findings were the only parameters significantly and independently associated with persistent airflow obstruction, but the groups were not different with respect to smoking history, atopic status, hospital admissions, quality-of-life scores and corticosteroid treatment. Hence, those with more severe obstruction had evidence of greater airway inflammation and more airway abnormalities, despite similar treatment. Similarly, among 132 patients in the Netherlands with severe asthma who had at least one exacerbation in the previous year or who were receiving maintenance oral corticosteroids, only sputum eosinophilia was independently associated with persistent airflow obstruction, with an odds ratio of 8.9 [15].

There is little doubt that inflammation contributes to persistent airflow obstruction in asthma, and that chronic inflammation is associated with exacerbations [16], but does reducing inflammation provide a better outcome? Can a decline in lung function be prevented? This question has been addressed in epidemiological and clinical studies, with as yet no consistent answer. In the Childhood Asthma Management Program [17], treatment with ICS did not result in any higher postbronchodilator lung function after 3 yrs, compared with nedocromil or placebo. This may appear surprising given that patients using ICS had improved asthma control and, therefore, fewer exacerbations. Other studies do suggest a benefit of ICS. Among patients followed for a median of $23 \mathrm{yrs}$, the mean annual decline in FEV1 in males was $20.6 \mathrm{~mL} \cdot \mathrm{yr}^{-1}$ less after ICS initiation, compared with before treatment [18]. In patients with a smoking history of $<5$ pack-yrs, greater benefit was seen, with a decline of $36.8 \mathrm{~mL} \cdot \mathrm{yr}^{-1}$ less, compared with before ICS treatment. There were minimal effects in females or males with a smoking history of $>5$ pack-yrs. In the Perth study [6], symptoms improved and the risk of mortality decreased with increased use of ICS, despite ongoing airflow obstruction.

Patients in the study by BAI et al. [13] had, on average, experienced symptoms for 17 (interquartile range 11-24) yrs before attending the clinic for assessment and treatment. SELROOS et al. [19] reported a reduced functional response to therapy among those with a longer delay between the onset of asthma and initiation of ICS. Similarly, HAAHTELA [20] demonstrated in a Finnish cohort that patients who used only an inhaled bronchodilator for 2 yrs after first diagnosis before commencing treatment with ICS had a reduced response to subsequent treatment, again suggesting that damage to the airway (remodelling) had already occurred.

There is a pressing need for long-term studies examining treatments and outcomes in asthma. If exacerbations predict decline in function, does reduction in exacerbations reduce that decline? This is logical, but it has not been proven. Many clinical trials over recent decades have focused on exacerbations as the primary outcome, which is appropriate due to the major impact of exacerbations on patients' quality of life and on healthcare utilisation costs. The study by BAI et al. [13] suggests that reduction in the frequency of exacerbations may also be an important goal in order to reduce the progressive decline in lung function in many patients with asthma.

\section{REFERENCES}

1 Lange P, Parner J, Vestbo J, Schnohr P, Jensen G. A 15-year follow-up study of ventilatory function in adults with asthma. N Engl J Med 1998; 339: 1194-1200.

2 Peat JK, Woolcock AJ, Cullen K. Rate of decline of lung function in subjects with asthma. Eur J Respir Dis 1987; 70: 171-179.

3 Brown PJ, Greville HW, Finucane KE. Asthma and irreversible airflow obstruction. Thorax 1984; 39: 131-136.

4 Corris PA, Dark JH. Aetiology of asthma: lessons from lung transplantation. Lancet 1993; 341: 1369-1371.

5 Vonk JM, Jongepier H, Panhuysen CI, Schouten JP, Bleecker ER, Postma DS. Risk factors associated with the presence of irreversible airflow limitation and reduced transfer coefficient in patients with asthma after 26 years of follow up. Thorax 2003; 58: 322-327.

6 Panizza JA, James AL, Ryan G, de Klerk N, Finucane KE. Mortality and airflow obstruction in asthma: a 17-year follow-up study. Intern Med J 2006; 36: 773-780.

7 Phelan PD, Robertson CF, Olinsky A. The Melbourne Asthma Study: 1964-1999. J Allergy Clin Immunol 2002; 109: 189-194.

8 Sears MR, Greene JM, Willan AR, et al. A longitudinal, population-based, cohort study of childhood asthma followed to adulthood. N Engl J Med 2003; 349: 1414-1422.

9 Rasmussen F, Taylor DR, Flannery EM, et al. Risk factors for airway remodeling in asthma manifested by a low postbronchodilator FEV1/vital capacity ratio: a longitudinal 
population study from childhood to adulthood. Am J Respir Crit Care Med 2002; 165: 1480-1488.

10 Apostol GG, Jacobs DR, Tsai AW, et al. Early life factors contribute to the decrease in lung function between ages 18 and 40: the Coronary Artery Risk Development in Young Adults study. Am J Respir Crit Care Med 2002; 166: 166-172.

11 Van Schayck CP, Dompeling E, Van Herwaarden CL, Wever AMJ, Van Weel C. Interacting effects of atopy and bronchial hyperresponsiveness on the annual decline in lung function and the exacerbation rate in asthma. Am Rev Respir Dis 1991; 144: 1297-1301.

12 Rennard SI, Farmer SG. Exacerbations and progression of disease in asthma and chronic obstructive pulmonary disease. Proc Am Thorac Soc 2004; 1: 88-92.

13 Bai TR, Vonk JM, Postma DS, Boezen HM. Severe exacerbations predict excess lung function decline in asthma. Eur Respir J 2007; 30: 452-456.

14 Bumbacea D, Campbell D, Nguyen L, et al. Parameters associated with persistent airflow obstruction in chronic severe asthma. Eur Respir J 2004; 24: 122-128.
15 ten Brinke A, Zwinderman AH, Sterk PJ, Rabe KF, Bel EH. Factors associated with persistent airflow limitation in severe asthma. Am J Respir Crit Care Med 2001; 164: 744-748.

16 Bousquet J, Jeffery PK, Busse WW, Johnson M, Vignola AM. Asthma. From bronchoconstriction to airways inflammation and remodeling. Am J Respir Crit Care Med 2000; 161: 1720-1745.

17 Long-term effects of budesonide or nedocromil in children with asthma. The Childhood Asthma Management Program Research Group. N Engl J Med 2000; 343: 1054-1063.

18 Dijkstra A, Vonk JM, Jongepier $\mathrm{H}$, et al. Lung function decline in asthma: association with inhaled corticosteroids, smoking and sex. Thorax 2006; 61: 105-110.

19 Selroos O, Pietinalho A, Löfroos AB, Riska H. Effect of early versus late intervention with inhaled corticosteroids in asthma. Chest 1995; 108: 1228-1234.

20 Haahtela T. Airway remodelling takes place in asthma what are the clinical implications? Clin Exp Allergy 1997; 27: 351-353. 